\title{
Trends in lung cancer, chronic obstructive lung disease, and emphysema death rates for England and Wales 1941-85 and their relation to trends in cigarette smoking
}

Peter N Lee, John S Fry, Barbara A Forey

\begin{abstract}
Trends in smoking associated respiratory diseases in England and Wales during 1941-85 have been studied, with careful attention to problems caused by changes in classification of cause of death. Three diseases were selected for analysis: lung cancer, emphysema, and chronic obstructive lung disease. During 1971-85 deaths that would previously have been certified under chronic bronchitis have increasingly tended to be classified under chronic airways obstruction. The definition of chronic obstructive lung disease that was used includes both terms to avoid the artificial decline caused by consideration of chronic bronchitis in isolation. Age specific rates for all three diseases show a pronounced cohort (period of birth) pattern, rates for men rising up to the rates for those born shortly after the turn of the century and then declining, and rates for women peaking in the cohort born 20-25 years later. For chronic obstructive lung disease, but not for lung cancer and emphysema, the cohort peak is superimposed on a sharply declining downward trend. In both sexes cohort patterns of cumulative cigarette consumption peak at a time broadly similar to those seen for the three diseases. Trends in cigarette consumption, however, cannot explain the underlying steeply declining rate of chronic obstructive lung disease. Nor can they fully explain the declining trends in lung cancer and emphysema rates in younger men and women.
\end{abstract}

Trends in lung cancer death rates in England and Wales have been examined by various authors. ${ }^{1-7}$ Some ${ }^{57}$ have used the method of Osmond and Gardner, ${ }^{8}$ which seeks to explain variation in cancer rates in terms of age, period (of death), or cohort (period of birth) effects. (A fuller description of the method is given under "Statistical methods" below.) Age specific lung cancer death rates have been shown to be strongly related to cohort and, given cohort, to be little related to period. ${ }^{57}$ For men rates rise as far as the cohort born around 1900 and then fall, but for women the peak is reached in the cohort born about 20-25 years later. The rising cohort values in the two sexes correspond broadly with what is known about the increases that occurred in cigarette smoking in the early decades of the century. ${ }^{5}$ The decreasing tar content of cigarettes $^{910}$ may have contributed to the decline, ${ }^{1}$ but seemingly cannot explain it all. $^{511-13}$

It has been suggested that chronic bronchitis trends show a cohort pattern identical to that for lung cancer and, in addition, a clearly observed period decline. ${ }^{7}$ This decline has been attributed to social improvements, cleaner air, decreasing tar delivery from cigarettes, and advances in treatment. ${ }^{2}$ More recently ${ }^{7}$ it has been attributed to decreasing childhood respiratory infection, though this would seem more likely to cause a cohort effect. ${ }^{11}$ The difficulty of separating period and cohort effects in the presence of a general downward drift in rates ${ }^{14-16}$ may partly explain this.

In this paper we question whether it is entirely appropriate to include in chronic bronchitis deaths from both bronchitis and emphysema, which often can be separated into clinically distinct categories, and we compare and contrast trends in these diseases with those for lung cancer and study their relation to cigarette smoking. To counter criticisms ${ }^{4}$ of previous estimates ${ }^{1}$ we have used revised estimates of prewar cigarette consumption by age and sex.

\section{Methods}

MORTALITY AND POPULATION DATA

Data by five year age group (up to $85+$ years) and sex were obtained for the period 1941-85 from the Registrar General's statistical reviews and the data of the Office of Population Censuses and Surveys. ${ }^{17} 18$ Following Case et al, data for civilians and non-civilians have been combined for the years 1941-9; subsequently data were for the home population. Where a complete age breakdown was not available, estimates were based on sex specific proportions by age in adjacent years.

\section{DEFINITION OF DISEASES}

Changes made at each revision of the International Classification of Diseases (ICD) make it impossible to define diseases that can be studied with complete consistency over the period in question. Preliminary work resulted in the conclusion, however, that lung cancer, chronic obstructive lung disease, and 
Table 1 ICD codes corresponding to disease categories

\begin{tabular}{|c|c|c|c|c|c|}
\hline \multirow[b]{2}{*}{ Disease category ${ }^{\star}$} & \multicolumn{5}{|c|}{ Year/ICD revision } \\
\hline & $\begin{array}{l}1941-9 \\
5 t h\end{array}$ & $\begin{array}{l}1950-7 \\
6 t h\end{array}$ & $\begin{array}{l}1958-67 \\
7 t h\end{array}$ & $\begin{array}{l}1968-78 \\
8 t h\end{array}$ & $\begin{array}{l}1979-85 \\
9 t h\end{array}$ \\
\hline Lung cancer (LC) & $47(b)$ & $\begin{array}{l}162 \\
163\end{array}$ & $\begin{array}{l}162 \\
163\end{array}$ & 162 & 162 \\
\hline $\begin{array}{l}\text { Emphysema (EM) } \\
\text { Chronic bronchitis (CB) } \\
\text { Chronic airways obstruction and } \\
\text { other respiratory disease }(\mathrm{CAO})\end{array}$ & $\begin{array}{l}113 \\
106(\mathrm{~b}) \\
114(\mathrm{e})\end{array}$ & $\begin{array}{l}527 \cdot 1 \\
502 \\
527 \cdot 0 \\
527 \cdot 2\end{array}$ & $\begin{array}{l}527 \cdot 1 \\
502 \\
527 \cdot 0 \\
527 \cdot 2\end{array}$ & $\begin{array}{l}492 \\
491 \\
519\end{array}$ & $\begin{array}{l}492 \\
491 \\
496 \\
518 \\
519\end{array}$ \\
\hline Unspecified bronchitis (UB) & $106(c)$ & 501 & 501 & 490 & 490 \\
\hline $\begin{array}{l}\text { Chronic obstructive pulmonary } \\
\text { disease (COPD) } \\
\text { "Barker and Osmond bronchitis" }\end{array}$ & $\begin{array}{l}\text { Sum of } \\
106(b) \\
106(c) \\
113\end{array}$ & $\begin{array}{l}\mathrm{CAO}+\mathrm{UB} \\
501 \\
502 \\
527\end{array}$ & $\begin{array}{l}501 \\
502 \\
527 \cdot 1\end{array}$ & $\begin{array}{l}490 \\
491 \\
492\end{array}$ & $\begin{array}{l}490 \\
491 \\
492\end{array}$ \\
\hline
\end{tabular}

^Abbreviation used.

emphysema could be defined consistently enough to allow useful study of trends, provided that account was taken of information available from "bridge coding" tables (see below).

The ICD codes were used to define the various diseases of interest and the abbreviations we have adopted are summarised in table 1 , with further explanation given in the following text:

Lung cancer The totals are dominated throughout by primary cancer of the lung. Inclusion of pleural cancer (ICD 5th and 8th revisions), tracheal cancer (revisions 6-9), or mediastinal cancer (revision 8) has little practical effect.

Emphysema Data are available for emphysema separately except in 1950-7, where only figures for the combined code 527 ("other diseases of lung and pleural cavity") are presented in the source tables. As $527 \cdot 1$ forms the dominant part of 527 for middle and older ages, however, we could estimate data for this category satisfactorily by applying age and sex specific factors based on 1958-67 data.

Bronchitis and emphysema When both chronic bronchitis and emphysema were recorded on the death certificate, emphysema was excluded for the purposes of determining the underlying cause according to the ICD classification rules.

Asthmatic bronchitis From the 7 th revision asthma not indicated as allergic with mention of bronchitis was included under bronchitis. Under the 9th revision asthmatic bronchitis was moved to asthma, but asthmatic chronic bronchitis continued to be included under bronchitis.

Chronic airways obstruction and other respiratory disease As a result of changes in belief about the role of chronic sputum production and chronic bronchitis the term chronic airways obstruction was introduced into the 8th revision of the ICD as code 519.9. It became increasingly fashionable during the 1970 s and a full code, 496, was assigned to it in the 9th revision. Table 2 shows clearly that trends in chronic bronchitis or chronic airways obstruction individually will be misleading in recent years and that the combination of the two is the only stable entity worth studying. "Other respiratory disease" has been included in our definition of chronic airways obstruction (and chronic obstructive lung disease) because data from chronic airways obstruction were not presented separately until 1976. Although consisting of a variable mixture of diseases in earlier ICD revisions, numbers of deaths were

Table 2 Numbers of deaths (all ages) from chronic bronchitis, chronic airways obstruction, and other respiratory disease, 1972-84*

\begin{tabular}{|c|c|c|c|c|c|c|c|}
\hline Disease & 1972 & 1974 & 1976 & 1978 & 1980 & 1982 & 1984 \\
\hline \multicolumn{8}{|l|}{ MEN } \\
\hline Chronc bronchitis & 19939 & 17479 & 16731 & 15382 & 12786 & 10966 & 8391 \\
\hline Chronic airways obstruction & - & - & $950^{\star}$ & 1613 & 2931 & 5103 & 7846 \\
\hline Other respiratory disease & - & - & 473 & 561 & 362 & 490 & 540 \\
\hline Combined & 574 & 712 & 1423 & 2174 & 3293 & 5603 & 8386 \\
\hline Total & 20513 & 18191 & 18154 & 17556 & 16079 & 16559 & 16777 \\
\hline \multicolumn{8}{|l|}{ WOMEN } \\
\hline Chronic bronchitis & 6184 & 5555 & 7031 & 5106 & 4417 & 4147 & 3402 \\
\hline Chronic airways obstruction & - & - & $321 \dagger$ & 565 & 1055 & 1907 & 3047 \\
\hline Other respiratory disease & - & - & 484 & 499 & 434 & 612 & 620 \\
\hline Combined & 382 & 495 & 805 & 1064 & 1489 & 2519 & 3667 \\
\hline Total & 6566 & 6050 & 7836 & 6170 & 5906 & 6666 & 7069 \\
\hline
\end{tabular}

*Unavailable data indicated by - . †For 1976 deaths from chronic airways obstruction were not given directly by the Office of Population Censuses and Surveys and were estimated by subtraction. 
Table 3 Numbers of deaths (age 40 or over) from acute, chronic, and unspecified bronchitis; chronic airways obstruction; and emphysema in 1941, 1950, 1970, and 1985

\begin{tabular}{|c|c|c|c|c|}
\hline Disease & 1941 & 1950 & 1970 & 1985 \\
\hline \multicolumn{5}{|l|}{ MEN $\quad \ldots$} \\
\hline \multicolumn{5}{|l|}{ Bronchitis } \\
\hline Acute & 2995 & 1693 & 796 & 298 \\
\hline Chronic & 10974 & 14115 & 19882 & 8092 \\
\hline Unspecified & 3165 & 1265 & 591 & 173 \\
\hline \multicolumn{5}{|l|}{ Chronic airways obstruction and "other" } \\
\hline respiratory disease & 164 & 51 & 293 & 10330 \\
\hline Emphysema & 354 & 531 & 1009 & 700 \\
\hline \multicolumn{5}{|l|}{ WOMEN } \\
\hline \multicolumn{5}{|l|}{ Bronchitis } \\
\hline Acute & 3999 & 2294 & 797 & 463 \\
\hline Chronic & 6869 & 6832 & 5862 & 3559 \\
\hline Unspecified & 2974 & 1210 & 600 & 257 \\
\hline \multicolumn{5}{|l|}{ Chronic airways obstruction and "other" } \\
\hline respiratory disease & 56 & 25 & 718 & 4977 \\
\hline Emphysema & 96 & 89 & 287 & 1028 \\
\hline
\end{tabular}

always small.

Acute, chronic, and unspecified bronchitis Our classification of chronic obstructive lung disease has excluded acute bronchitis (ICD 5 th revision $106(a), 6$ th and 7 th revisions 500 , 8th and 9 th revision 466), which is believed to be aetiologically distinct from chronic bronchitis. It has, however, included deaths from bronchitis not specified as acute or chronic. As shown in table 3 , numbers of deaths from unspecified bronchitis in recent years have been relatively low, and any upward bias by inclusion of some true acute bronchitis deaths among them would be very small indeed. Although such bias was larger from 1941 to 1950 it probably never exceeded $10 \%$ and no attempt has been made to adjust for it.

Barker and Osmond bronchitis There are two main differences between the definition of bronchitis used by Barker and Osmond ${ }^{7}$ and our definition of chronic obstructive lung disease. The most serious difference arises from their omission of deaths from chronic airways obstruction, which, as noted above, may have a major effect in the last 10 years or so. The other main difference is that their definition included emphysema as well as chronic bronchitis. As is evident from table 3, deaths from emphysema were fewer than those from chronic bronchitis and chronic airways obstruction combined, so that inclusion of emphysema deaths would have little effect on our conclusions for chronic obstructive lung disease. Separation of emphysema, however, as we will show, allows distinct differences in the trends for emphysema and chronic obstructive lung disease to be detected.

\section{BRIDGE CODE ADJUSTMENT}

Tables published by the Office of Population Censuses and Surveys ${ }^{20-23}$ gave the results, by age and sex, of "bridge coding" exercises, in which at each change to a new revision of the ICD deaths from the last year of the old revision are recoded according to the new revision. The Office of Population Censuses and Surveys also provided an unpublished table relating to the change from the 8 th to the 9 th revision. These tables were used to adjust rates to give estimates of the numbers of deaths that would have been recorded had the 9th revision of the ICD been in force throughout the period. The adjustment factors used, which affected lung cancer very little, are available on request.

\section{CIGARETTE SMOKING}

Annual data on cigarette smoking by the population of the United Kingdom were taken from Wald $e t a l^{4}$ and from Lee. ${ }^{9}$ Estimates of age and sex specific cigarette consumption for the years before 1946 were made by backward extrapolation (appendix A). These estimates were preferred to those given by Lee, ${ }^{9}$ which depend on a probably unjustified assumption that the age distribution of smoking was invariant by year before 1946, the date of the earliest survey of smoking habits.

\section{STATISTICAL METHODS}

Mortality data for a given cause of death for one sex were displayed as a rectangular array of death rates with nine time periods of death horizontally (left $1941-5$ to right $1981-5$ ) and nine age groups (top 40-44 to bottom 80-84). Diagonals of this table running from top left to bottom right represent people in the same birth cohort. Thus there is information on people born around 1900 (40-44 in 1941-5, 45-49 in $1946-50$, etc) for the whole age range, with lesser information for people born earlier and later. There is at least some information for people in 17 birth cohorts.

Trends in mortality can often be characterised by one or more of three types of effect: age, period, and cohort. Age effects are present for virtually every cause of death. Period effects typically occur as a result of changes affecting all age groups-for example, changes in diagnostic standards and cure rates, and introduction of an aetiological agent with a rapid effect. Cohort effects typically occur when people born at a given time are more exposed to an agent than people born at another time.

In the method of Osmond and Gardner ${ }^{6}$ rates are fitted by a product of age, period, and cohort effects. Results are usually presented graphically, fitted period and cohort values being relative to an average of 1 . Where no pronounced period effects are evident (that is, all values are close to 1 ), cohort effects have a simple interpretation. For example, a value of 1.2 would mean that in all age groups people in that birth cohort are $20 \%$ more likely to die from the disease of interest than average and $100 \%$ more likely to die from it than people in a cohort with the value $0 \cdot 6$. Similarly, where no substantial cohort effects are evident, period effects have a simple interpretation. It should be noted that, whereas all the fitted period values are relatively stable as there are full data on each age group for every period, this is not so for all the fitted cohort values, those for the earliest and latest cohorts being less stable. In particular, the estimate for the very latest cohort will be based only on a single data point for the youngest age group, where numbers of deaths may be small.

Further discussion of the Osmond and Gardner method is given in several 


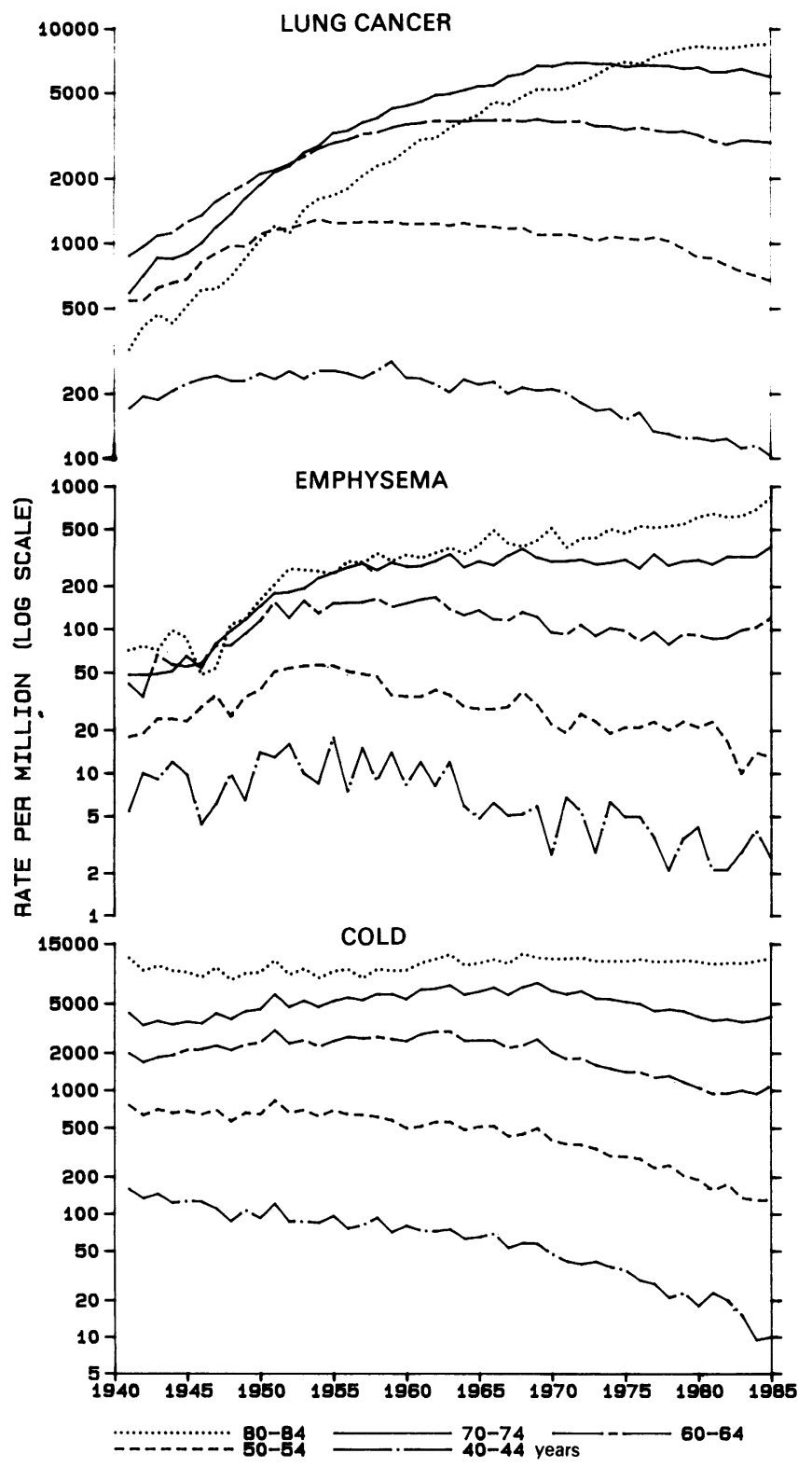

Figure 1 Trends in age specific male mortality rates (bridge code adjusted), 1941-85. COLD-chronic obstructive lung disease. The scales differ for the three diseases.

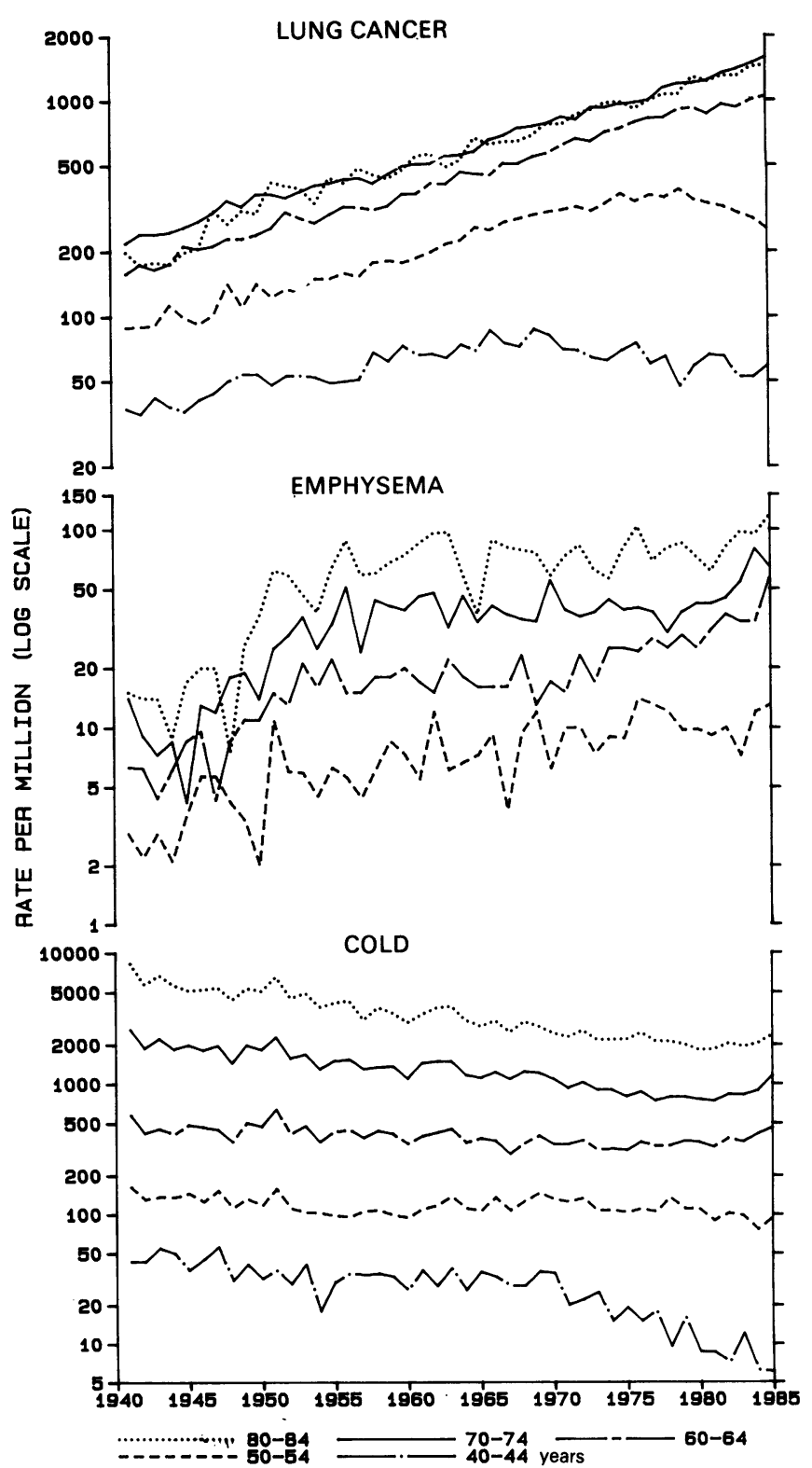

Figure 2 Trends in age specific female mortality rates (bridge code adjusted), 1941-85. COLD-chronic obstructive lung disease. The scales differ from those of figure 1. papers. ${ }^{5814-16}$ For our analyses we used either the method directly or log linear models equivalent to it derived by the GLIM system. ${ }^{25}$

\section{Results}

\section{MORTALITY RATES}

For men (fig 1) lung cancer rates in each age group rise to a peak and then (with the exception of the highest age group, 80-84) show a subsequent decline. Emphysema rates show a similar pattern, though the trends in the youngest age groups are less stable owing to small numbers of deaths. Peaks occur for cohorts of people born around the turn of the century in both diseases, though they do not exactly coincide. For chronic obstructive lung disease quite a different pattern is seen, with stronger downward trends in the younger age groups and peaks occurring earlier.

In women (fig 2) lung cancer rates have risen continuously in the older age groups, but evidence from the younger age groups, though the absolute values are smaller, is consistent with the peak occurring for the cohort born about 1925. As in men, trends for emphysema are not dissimilar to those for lung cancer, though greater fluctuations are evident. (Rates for 40-44 year olds were omitted from figure 2, often being based on only one or two deaths.) Again as in men, trends in chronic obstructive lung disease show a different pattern, with a general decline in rates.

\section{ANALYSIS OF OSMOND AND GARDNER}

Figures 3 (men) and 4 (women) show some of the results of fitting the method of Osmond and Gardner to the bridge code adjusted mortality data for five year age groups from 40-44 to 8084 for five year periods from 1941-5 to 1981-5. Age values are not shown in the figures but mortality increased smoothly with age for all three diseases and both sexes. The model generally fitted the data well, particularly for lung cancer and emphysema. Even for chronic obstructive lung disease, where the misfit was 


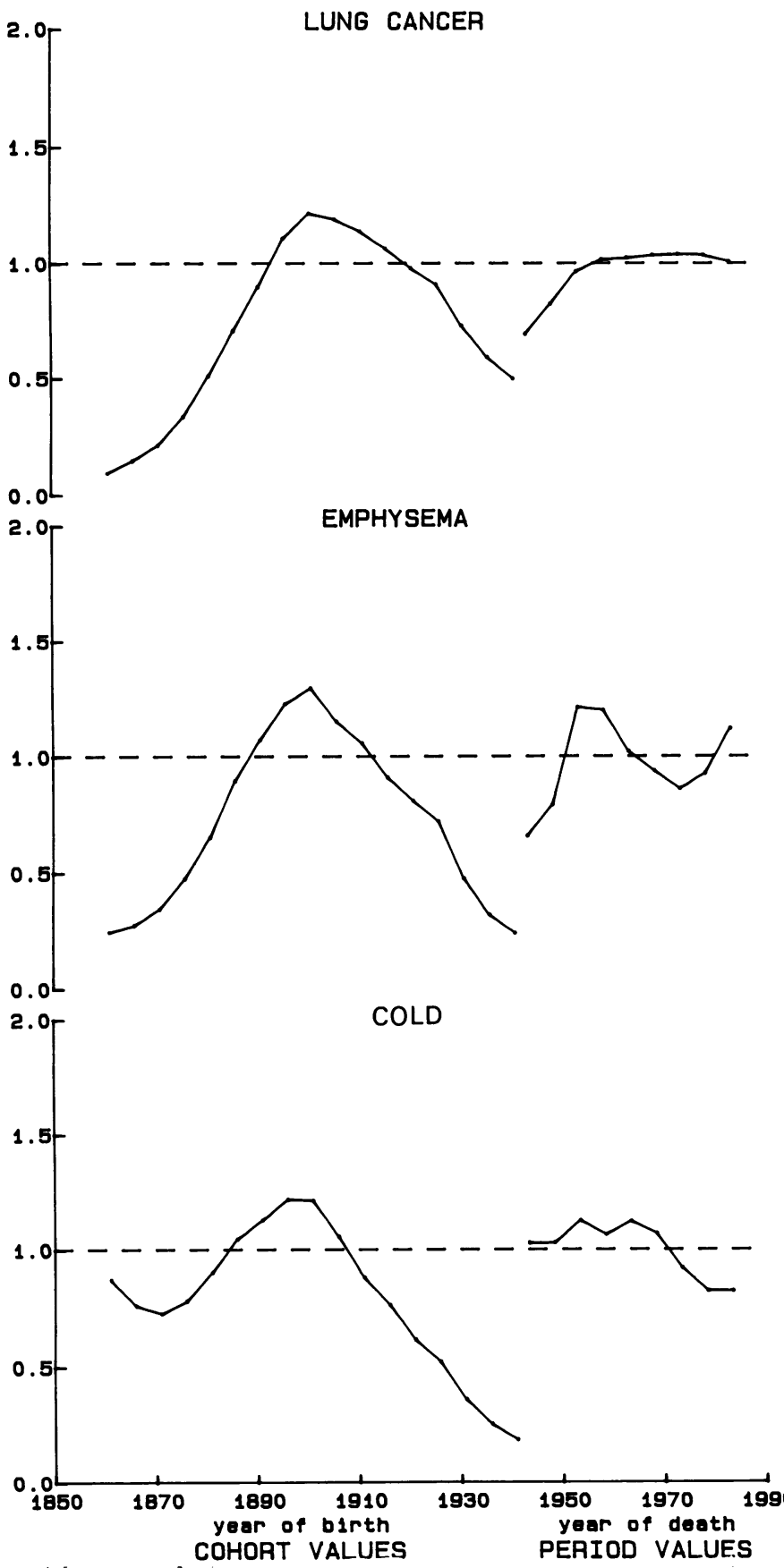

Figure 3 Cohort and period values, based on the analyszs of Osmond and Gardner, for men. COLD_chronic obstructive lung disease.
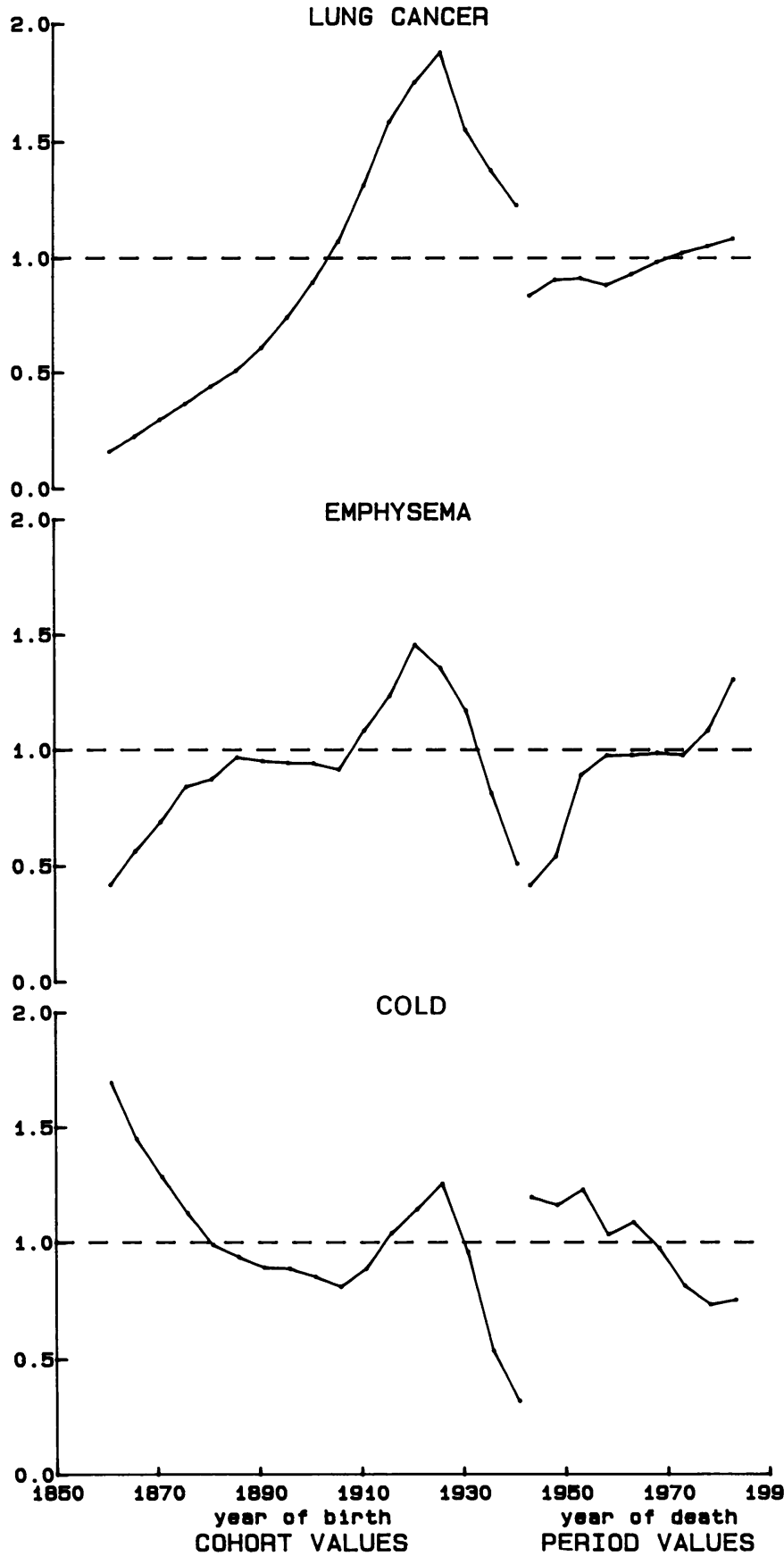

Figure 4 Cohort and period values, based on the analysis of Osmond and Gardner, for women. COLD-chronic obstructive lung disease. somewhat greater, the model explained about $99 \%$ of the variance unexplained simply by age.

With the exception of emphysema in women, the figures clearly show that cohort effects are much larger than period effects. This is also evident from results (not shown in detail) showing that the age-cohort model fitted the data considerably better than the age-periou model. Some of the period pattern for emphysema may partly be an artefact due to the difficulties of accurately adjusting for the change from the 5th to the 6th ICD revision and the limited data available.

The cohort patterns seen in figures 3 and 4 have two striking features. The first is the clear peak for each disease, occurring earlier (about 1900) for men and later (about 1925) for women. The second is the fact that for chronic obstructive lung disease the peaks in both sexes are superimposed on an underlying downward trend. All these diseases appear to have been affected by one agent but different birth cohorts were exposed differently, men being exposed earlier than women. For chronic obstructive lung disease there appears to be a second agent, which results in a continuing decline in mortality rates.

\section{RELATION OF TRENDS IN MORTALITY AND} SMOKING HABITS

Cumulative constant tar (CCT) cigarette consumption, estimated as described in the appendix, is plotted by age and sex against calendar year (fig 5) and year of birth (fig 6). Figure 5 may be compared with figures 1 and 2 , and figure 6 may be compared with the cohort patterns in figures 3 and 4.

There are several obvious similarities between the CCT cigarette consumption and 


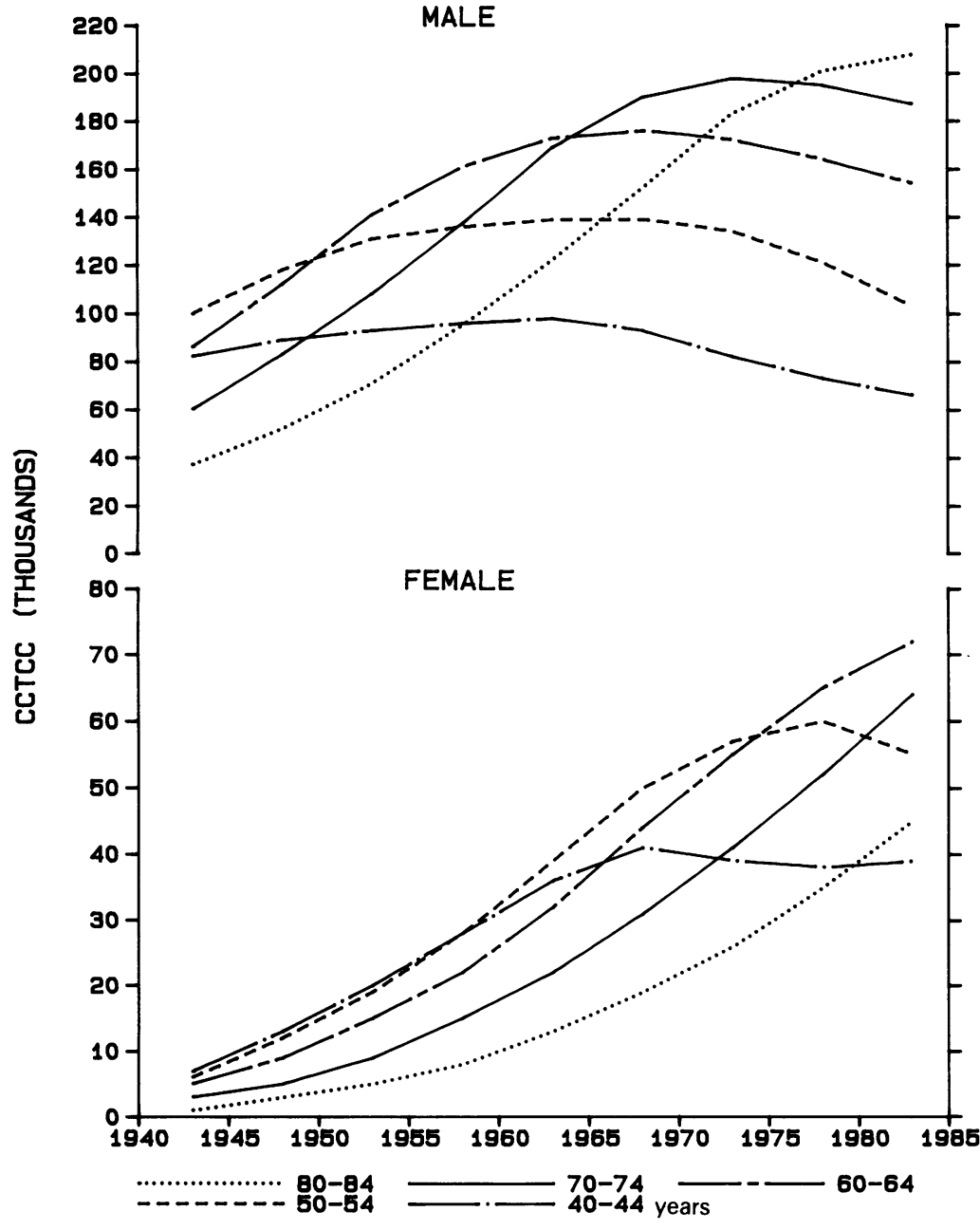

Figure 5 Cumulative constant tar cigarette consumption (CCTCC) by age and year, 1926-85. The scales differ for the two sexes.

mortality trends. For men the CCT cigarette consumption in each age group has risen with time and has now, except in the 80-84 year old age group, fallen from a peak (fig 5) corresponding closely to the lung cancer trends (fig 1). For women the fact that the CCT cigarette consumption is still rising in the age groups 60 $64,70-74$, and 80-84 (fig 5) corresponds to the continuing upward trends in lung cancer (fig 2). Furthermore, it is evident from figure 6 that the cohorts showing peak CCT cigarette consumption are earlier for men than for women, and that the difference is similar to the difference between figures 3 and 4 .

Where recent reductions in mortality rates are considered, however, particularly in the younger age groups, the correspondence with CCT cigarette consumption is much less good. This is seen more clearly for women than for men, though it can be seen in both sexes. This anomaly emerges from comparison of figures 4 and 6 . Figure 4 suggests that cohort values are similar for women born around 1910 and around 1940, whereas figure 6 shows that the later born group of women have smoked very much more. The anomaly is also evident from a direct comparison of trends in women of a given age (figs 2 and 5). This is shown more clearly in figure 7 for $40-44$ year olds: from 1950 to 1985 CCT cigarette consumption rose about threefold but lung cancer rates hardly changed. In particular, the fall in lung cancer from 1970 to 1985 is not explained by changes in CCT cigarette consumption. This anomaly persists when we use alternative estimates of CCT cigarette consumption based on different tar estimates or backward extrapolation procedures, and would be even greater if allowance were made for "compensation" (that is, smoking cigarettes with a reduced machine yield of tar and nicotine more intensely), which may be substantial. ${ }^{26}$ To allow closer correspondence between changes in lung cancer and changes in CCT cigarette consumption one would have to assume that there had been a decline in the "background" lung cancer rate (that is, unrelated to CCT cigarette consumption). The dashed line in fig 7 illustrates the order of magnitude of background rate that would have to be subtracted from the observed lung cancer rate to leave the residual rate reasonably well correlated with CCT cigarette consumption trends.

\section{Discussion}

Our analyses have clearly shown differences in mortality trends for chronic obstructive lung disease and emphysema. Whereas both show cohort patterns that peak at around the same birth year, the peaks for chronic obstructive lung disease are superimposed on a strong declining downward trend that is not present for emphysema. In the past, research workers have restricted attention to study of chronic bronchitis and emphysema combined (with or without asthma) and have not attempted to separate the diseases. Although perfect separation cannot be achieved (inevitably some deaths due to emphysema in which chronic bronchitis was also present will have been inappropriately coded as chronic bronchitis), and although problems due to ICD changes and the switch to use of the term chronic airways obstruction have had to be overcome, we believe that our results are relevant. Different diseases with different causes are present and our analysis suggests that the relative importance of the different causes is not the same.

Our analyses also show that trends in emphysema show a close correlation with trends in lung cancer, though the latter disease is much more frequent. The cohort patterns, peaking around 1990 in men and around 20-25 years later in women (figs 3 and 4) are similar in many respects to the trends in cumulative constant tar cigarette consumption shown in figures 5 and 6 . This is consistent with the considerable epidemiological evidence linking cigarette smoking closely to both diseases. ${ }^{2728}$

We have shown that chronic obstructive lung disease, though showing cohort peaks similar to those of lung cancer, has an additional sharp decline not evident for lung cancer. Barker and Osmond ${ }^{7}$ considered this decline to be period related rather than cohort related, but this was mainly because their mathematical method constrained the cohort trends for the two diseases to be the same. Their analysis, which excluded chronic airways obstruction, included emphysema, failed to take account of 


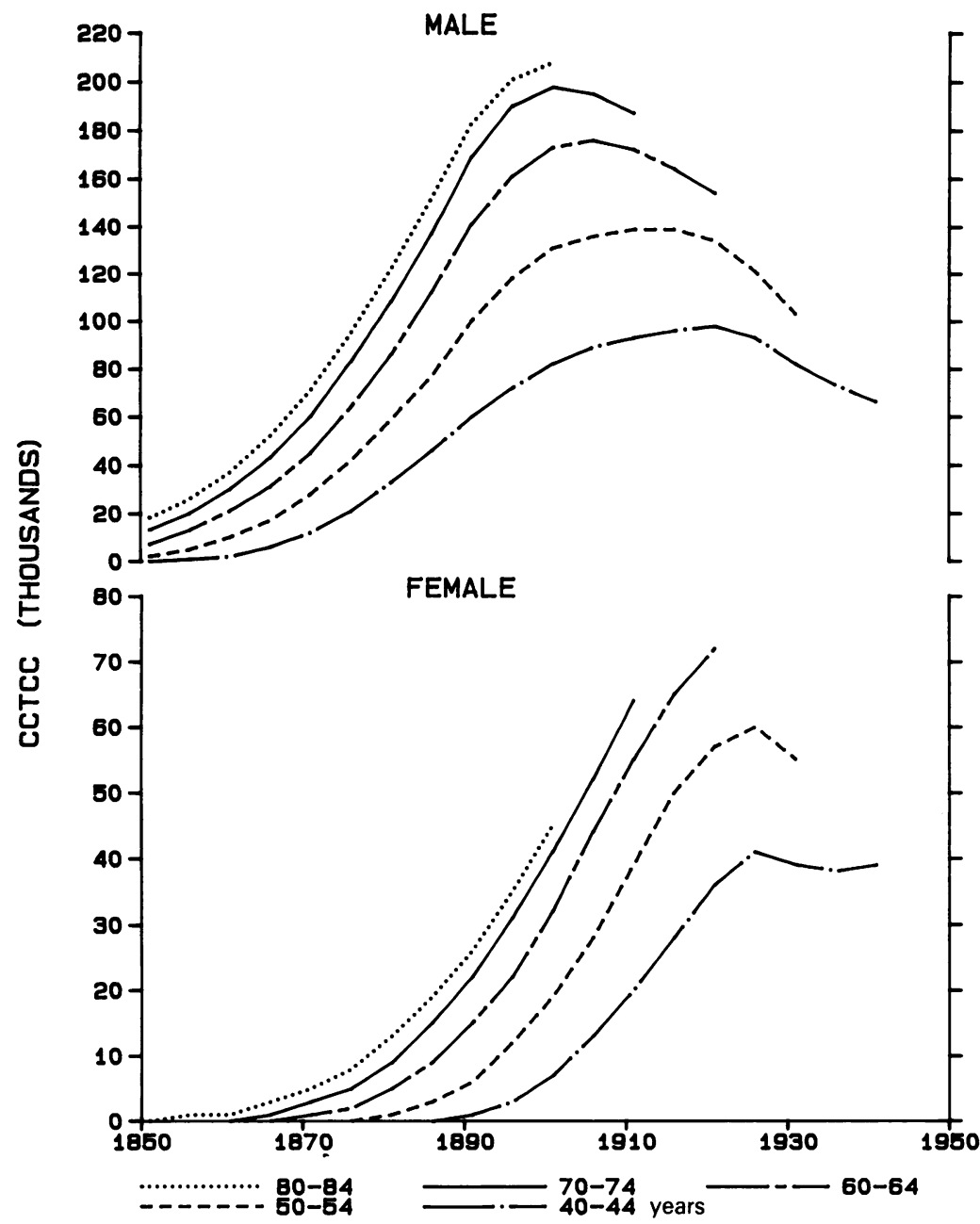

Figure 6 Cumulative constant tar cigarette consumption (CCTCC) by age and central year of birth, 1851-1966. The scales differ for the two sexes. infection would more logically appear as a cohort effect. Though our analysis is therefore more consistent with their theory than their analysis, we believe that it is premature to conclude that childhood respiratory infection is necessarily the agent responsible for the decline. We agree with Barker and Osmond that the Clean Air Act, which came into force only in 1956, cannot be a major explanation as the decline is too longstanding, being evident in cohorts born from 1863 onward.

Whatever the factor responsible for the decline in chronic obstructive lung disease (and this paper is not intended as a detailed discussion of possible causal factors in the aetiology of the three diseases considered), we suspect that it is also responsible for the huge social class gradient in death rates for chronic bronchitis, which was evident well before there was any real gradient in smoking by social class. ${ }^{29}$

Although the fact that the rise in lung cancer rates since 1940 can largely be explained by a rise in lifetime exposure to cigarettes is scarcely new, ${ }^{257}$ our analyses also highlight one striking anomaly, which has been given much less attention in published papers ${ }^{11-13}$ and which some have claimed does not exist. ${ }^{30}$ This anomaly, the failure of cigarette consumption trends to explain fully the trends in lung cancer rates in younger age groups from 1950 onwards, is evident in both sexes, and is particularly clear in women. As shown in figure 7 , women of age 40-44 have dramatically increased their cigarette smoking over the period 1941-85, but their lung cancer rate has increased only slightly. Although cumulative constant tar cigarette consumption is only one of several possible indices of exposure that might be used, this anomaly can hardly depend on the precise choice of index because smoking by women was so rare before the war. The fact that prewar cigarette consumption was so low does, of course, suggest a possible explanation of the anomaly-namely, that there is some factor other than smoking that was responsible for most of the lung cancers occurring in these women in the early 1940 s and that the effect of this factor has declined over time. Several considerations suggest that this explanation is a plausible one. Firstly, numerous epidemiological studies have shown that some lung cancer deaths occur among lifelong never smokers and that the proportion is particularly high among women and in studies carried out many years ago. ${ }^{27}$ Secondly, young women today are likely to have less exposure to occupational hazards and to air pollution than were young women 40 years ago. Thirdly, bronchitis may have a role in lung cancer and the decline may at least in part result from the same factor that caused the sharp decline in bronchitis rates. As trends in emphysema rates in younger men and women are similar to those for lung cancer clearly they too cannot easily be explained by trends in cigarette consumption.

In summary, though major features of the trends of the diseases studied correlate very well with trends in cumulative exposure to cigarettes, there is good reason to believe that other factors contribute to the aetiology of all

Figure 7 Lung cancer rate (-), cumulative constant tar cigarette consumption (CCTCC .....), and hypothesised "background" rate of lung cancer unrelated to cigarette consumption (--), for women aged $40-44,1941-85$. For comparisons with figures 1 and 2 note that this scale is arithmetic. 
three diseases. This is particularly so for chronic obstructive lung disease, where the declining effects of another factor are clearly evident at all ages; but it is also the case for lung cancer and emphysema, where downward trends in the younger age groups are too large and too early to be explained in terms of changes in the frequency or type of cigarettes smoked.

We thank Mr CD Gooch, who was involved in the early stages of this study, as well as Drs T Higenbottam and F J C Roe, the late this study, as well as Drs T Higenbottam and F J C Roe, the late advice. Mrs E K Marlow, Mrs D Morris, and Mrs A Pearson advice. Mrs E K Marlow, Mrs D Morris, and
assisted in the preparation of the manuscript.

\section{Appendix: Estimating age and sex specific cigarette consumption in the United Kingdom by backward extrapolation}

Survey data are available ${ }^{924}$ on manufactured cigarette consumption per adult by sex, five year age group, and five year period from 1946-50 onward. Earlier, data are available only for total sales of manufactured cigarettes by sex but not age. Estimates of age specific manufactured cigarette consumption per adult before 1946 have been presented, ${ }^{1}$ but these were calculated on the assumption that the age distribution of smoking is invariant before 1946, which is rather implausible." Here a more plausible assumption, based on relative consistency of cigarette consumption in different cohorts, has been used. The method may be summarised as follows:

1 Fit an age-cohort model to the known data from 1946 , to give a set of age and cohort estimates.
2 Extrapolate the cohort estimates to obtain values for earlier cohorts not represented in the data from 1946. 3 Use the age and cohort estimates to obtain preliminary consumption per adult figures for the earlier five year periods.

4 Using the preliminary consumption values and population figures for each earlier five year period, compute the implied all ages total cigarette consumption and compare with the actual figure to obtain a period correction factor.

5 Adjust the consumption figures for each earlier five year period using the appropriate correction factor.

6 Finally, adjust consumption estimates for each age group in each period by forming a weighted average of the unadjusted consumption estimate (weight 4) and those in the two adjacent cohorts (each weight 1 ). This makes it possible to relate consumption estimates more directly to specific cohorts because consumption in a specific five year period, for people whose age falls within a five year interval, relates to people born over a 10 year interval.

The resulting (adjusted) consumption estimates are shown in table A.

To convert these estimates to constant tar consumption estimates, we used factors of 0.477 for 1981-5, 0.544 for $1976-80,0.613$ for $1971-5,0.804$ for $1966-70$, and 1 for 1961-5 or earlier, on the basis of data provided by the Tobacco Advisory Council. ${ }^{924}$ Using alternative data on tar yields ${ }^{10}$ would not have affected our conclusions.

Given the consumption estimates and the tar factors, cumulative constant tar cigarette consumption in $1000 \mathrm{~s}$ was then calculated in a straightforward manner. Thus cumulative constant tar cigarette consumption for the male cohort born in 1941-5 for the age group 25-9 is calculated by summing five years at an average consumption of 921 (age 15-19, years 1956-60), five years at 3170 (age 20-24, years 1961-5), and two and a half years at $4267 \times 0.804$ (age 25-29, years 1966-70), to yield 29032 or a plotted value of 29 .

Table $A$ Estimated annual manufactured cigarette consumption per adult by age, sex, and period

\begin{tabular}{|c|c|c|c|c|c|c|c|c|c|c|c|c|c|c|}
\hline \multirow[b]{2}{*}{ Period } & \multicolumn{14}{|c|}{ Age (y) } \\
\hline & $15-19$ & $20-24$ & $25-29$ & $30-34$ & $35-39$ & $40-44$ & $45-49$ & $50-54$ & $55-59$ & $60-64$ & $65-69$ & $70-74$ & $75-79$ & $80-84$ \\
\hline \multicolumn{15}{|l|}{ MEN } \\
\hline 1891- & 20 & 45 & 49 & 45 & 42 & 39 & 33 & 29 & 23 & 18 & 12 & 9 & 6 & 4 \\
\hline 1896 & 85 & 208 & 239 & 214 & 200 & 184 & 160 & 137 & 111 & 86 & 61 & 41 & 30 & 21 \\
\hline 1901- & 205 & 521 & 620 & 559 & 505 & 468 & 410 & 351 & 285 & 221 & 157 & 105 & 77 & 54 \\
\hline $1906-$ & 357 & 923 & 1117 & 1026 & 928 & 832 & 735 & 634 & 517 & 400 & 286 & 191 & 139 & 98 \\
\hline 1911- & 500 & 1385 & 1681 & 1547 & 1422 & 1279 & 1093 & 949 & 779 & 603 & 432 & 289 & 210 & 148 \\
\hline 1916 & 699 & 1955 & 2512 & 2320 & 2138 & 1954 & 1672 & 1403 & 1160 & 905 & 647 & 433 & 315 & 221 \\
\hline 1921- & 733 & 2218 & 2960 & 2907 & 2680 & 2459 & 2141 & 1798 & 1445 & 1136 & 822 & 548 & 398 & 281 \\
\hline $1926-$ & 762 & 2284 & 3154 & 3180 & 3129 & 2875 & 2508 & 2143 & 1722 & 1307 & 951 & 639 & 464 & 327 \\
\hline 1931- & 811 & 2445 & 3406 & 3592 & 3626 & 3546 & 3103 & 2656 & 2170 & 1651 & 1163 & 786 & 575 & 405 \\
\hline 1936 & 927 & 2733 & 3778 & 4005 & 4235 & 4248 & 3959 & 3404 & 2782 & 2153 & 1517 & 992 & 731 & 518 \\
\hline 1941- & 1070 & 3146 & 4306 & 4551 & 4838 & 5075 & 4850 & 4439 & 3645 & 2824 & 2025 & 1327 & 945 & 675 \\
\hline 1946 & 918 & 3033 & 4324 & 4494 & 4716 & 4972 & 4955 & 4721 & 4226 & 3249 & 2248 & 1491 & 1085 & 764 \\
\hline $1951-$ & 761 & 2637 & 4048 & 4365 & 4425 & 4587 & 4603 & 4527 & 4233 & 3502 & 2380 & 1557 & 1183 & 840 \\
\hline $1956-$ & 921 & 2727 & 3940 & 4312 & 4582 & 4725 & 4737 & 4643 & 4338 & 3752 & 2717 & 1823 & 1387 & 985 \\
\hline $1961-$ & 1133 & 3170 & 4080 & 4130 & 4383 & 4660 & 4670 & 4588 & 4285 & 3747 & 3007 & 2135 & 1633 & 1150 \\
\hline 1966 & 1200 & 3333 & 4267 & 4115 & 4240 & 4470 & 4372 & 4238 & 3987 & 3532 & 2980 & 2278 & 1737 & 1228 \\
\hline 1971- & 1289 & 3460 & 4315 & 4248 & 4272 & 4362 & 4418 & 4223 & 3847 & 3480 & 3022 & 2353 & 1720 & 1273 \\
\hline 1976 & 1228 & 3317 & 4130 & 4067 & 4077 & 4080 & 4020 & 4155 & 3737 & 3333 & 2862 & 2193 & 1748 & 1295 \\
\hline 1981- & 1000 & 2690 & 3388 & 3373 & 3423 & 3365 & 3323 & 3253 & 3190 & 2720 & 2347 & 1798 & 1458 & 1165 \\
\hline \multicolumn{15}{|l|}{ WOMEN } \\
\hline 1921- & 13 & 30 & 37 & 37 & 35 & 35 & 34 & 28 & 24 & 18 & 13 & 9 & 5 & 3 \\
\hline 1926 & 38 & 100 & 130 & 134 & 123 & 120 & 118 & 101 & 83 & 66 & 46 & 32 & 20 & 12 \\
\hline 1931- & 75 & 205 & 266 & 274 & 260 & 247 & 241 & 206 & 171 & 132 & 95 & 66 & 41 & 25 \\
\hline 1936 & 133 & 367 & 486 & 497 & 470 & 458 & 437 & 371 & 305 & 240 & 168 & 120 & 75 & 44 \\
\hline 1941- & 274 & 751 & 998 & 1040 & 978 & 953 & 929 & 769 & 628 & 490 & 348 & 242 & 152 & 92 \\
\hline 1946 & 287 & 993 & 1406 & 1506 & 1385 & 1331 & 1331 & 1122 & 892 & 736 & 534 & 373 & 230 & 137 \\
\hline 1951- & 253 & 920 & 1512 & 1688 & 1588 & 1515 & 1550 & 1302 & 1038 & 812 & 592 & 410 & 255 & 150 \\
\hline 1956 & 336 & 1007 & 1598 & 1990 & 1983 & 1982 & 2035 & 1685 & 1330 & 1027 & 700 & 488 & 298 & 180 \\
\hline 1961- & 497 & 1385 & 1915 & 2137 & 2307 & 2420 & 2493 & 2125 & 1685 & 1300 & 893 & 630 & 385 & 223 \\
\hline 1966 & 719 & 1882 & 2388 & 2368 & 2403 & 2633 & 2705 & 2408 & 2053 & 1568 & 1073 & 770 & 463 & 260 \\
\hline 1971- & 947 & 2358 & 2878 & 2807 & 2720 & 2893 & 3075 & 2830 & 2395 & 1922 & 1312 & 902 & 578 & 330 \\
\hline 1976 & 983 & 2553 & 3055 & 3077 & 3095 & 3010 & 3180 & 3222 & 2805 & 2182 & 1570 & 1070 & 683 & 428 \\
\hline 1981- & 724 & 2147 & 2713 & 2722 & 2835 & 2887 & 2797 & 2822 & 2725 & 2263 & 1615 & 1087 & 762 & 475 \\
\hline
\end{tabular}


1 Todd GF, Lee PN, Wilson MJ. Cohort analysis of cigarette smoking and of mortality from four associated diseases. London: Tobacco Research Council, 1976. (Tobacco Research Council Occasional Paper 3.).

2 Royal College of Physicians. Smoking or health: the third report from the Royal College of Physicians of London. London: Pitman, 1977.

3 Townsend JL. Smoking and lung cancer: a cohort data study of men and women in England and Wales 1935-70. $J R$ Statist $\operatorname{Soc}(A)$ 1978;141:95-107.

4 Doll R, Peto R. The causes of cancer: quantitative estimates of avoidable risks of cancer in the United States today. $J$ Natl Cancer Inst 1981;66:1191-308.

5 Osmond C, Gardner MJ, Acheson ED, Adelstein AM. Trends in cancer mortality 1951-1980. Analyses by period of birth and death. London: HMSO, 1983. (Office of Population Censuses and Surveys, series DHI No 11.)

6 Stevens RG, Moolgavkar SH. A cohort analysis of lung cancer and smoking in British males. Am J Epidemiol 1984;119:624-41.

7 Barker DJP, Osmond C. Childhood respiratory infection and adult chronic bronchitis in England and Wales. $\mathrm{Br}$ Med J 1986;293:1271-5.

8 Osmond C, Gardner MJ. Age, period and cohort models applied to cancer mortality rates. Stats Med 1982;1: 245-59.

9 Lee PN. Statistics of smoking in the United Kingdom. London: Tobacco Research Council, 1976 (with annual supplements). (Tobacco Research Council Research supplemer 1).

10 Wald N, Doll R, Copeland G. Trends in tar, nicotine and carbon monoxide yields of UK cigarettes manufactured since 1934. Br Med J 1981;282:763-5.

11 Lee PN. Childhood respiratory infection and adult chronic bronchitis in England and Wales [letter]. $\mathrm{Br} M e d \mathrm{~J}$ 1987;294:118.

12 Froggatt $P$ (chairman). Fourth report of the Independent Scientific Committee on Smoking and Health, London, HMSO, 1988.

13 Froggatt Sir P, Wald N. The role of nicotine in the tar reduction programme. In: Wald N, Froggatt $\mathrm{P}$, eds. Nicotine, smoking and the low tar programme. Oxford University Press, 1989:229-35.

14 Holford TR. The estimation of age, period and cohort effects for vital rates. Biometrics 1983;39:311-24.
15 Clayton D, Schifflers E. Models for temporal variation in cancer rates. I: Age-period and age-cohort models. Stats Med 1987;6:449-67.

16 Clayton D, Schifflers E. Models for temporal variation in cancer rates. II: Age-period-cohort models. Stats Med 1987;6:469-81.

17 Registrar General. Statistical review of England and Wales Part I: Tables, medical. London: HMSO, 1941 et seq.

18 Office of Population Censuses and Surveys. Mortality statistics. Cause. London, HMSO, 1974 et seq.

19 Case RAM, Coghill C, Davies JM, et al. Serial mortality tables. Neoplastic diseases. Vol 1: England and Wales $1911-$ 70. London: Institute of Cancer Research, 1978.

20 Registrar General. Statistical review of England and Wales, 1948-49. Text, medical. London: HMSO, 1950 (appendix C).

21 Registrar General. Statistical review of England and Wales, 1957. Part III: London, HMSO, 1958 (appendix B).

22 Registrar General. Statistical review of England and Wales, 1967. Part III. London: HMSO, 1968 (appendix A).

23 Office of Population Censuses and Surveys. Mortality statistics, 1978. London, HMSO, 1979.

24 Wald N, Kiryluk S, Darby S, Doll R, Pike M, Peto R. UK smoking statistics. Oxford: Oxford University Press, 1988.

25 Baker RJ, Nelder JA. The GLIM system. Release 3. Generalised linear interactive modelling. Oxford: Numerical Algorithms Group, 1978.

26 Russell MAH, Jarvis MJ, Feyerabend C, Saloojee Y. Reduction of tar, nicotine and carbon monoxide intake in low tar smokers. J Epidemiol Commun Health 1986;40: low tar

27 US Surgeon General. The health consequences of smoking. Cancer. A report of the Surgeon General. Washington DC: US Department of Health and Human Services, 1982

28 US Surgeon General. The health consequences of smoking. Chronic obstructive lung disease. A report of the Surgeon General. Washington, DC: US Department of Health and General. Washington, D

29 Todd GF. Social class variations in cigarette smoking and in mortality from associated diseases. London: Tobacco Research Council, 1976. (Tobacco Research Council Occupational Paper 2.)

30 Barker DJP, Osmond C. Childhood respiratory infection and adult chronic bronchitis in England and Wales [letter]. $\mathrm{Br} \mathrm{Med} J$ 1987;294:118. 